eranium, from the state of its sutures and its dentition that of an aged male, is remarkable for its size in comparison with the short stature of its owner, and for its simian or pithecoid characters. The skull is dolichocephalous (index 75), and remarkable for its thick bones, its flattened cranial vault, enormous browridges (which are more prominent than in the original Neanderthal cranium), with a deep groove above them stretching from one orbital process to the other, for its much depressed occipital "bulging," for the backward position of the foramen magnum, the flattening of the occipital condyles, and the feeble development of the mastoid processes. The very prognathous face has large and prominent orbits, with a deep depression between them separating the short and very broad nose from the forehead. The upper maxillary differs widely from that in all living races of mankind, in projecting in front, into a sort of muzzle; while the palatine contour is very simian. The lower jaw is remarkable for its massiveness, the great width of its condyle, the shallowness of its sigmoid notch, the obliquity of its symphysis, and the absence of chin.

The La Chapelle-aux-Saints cranium, therefore, presents the characters, in some respects exaggerated, which distinguish the Neanderthal and Spy calvaria, all of which, though widely spread over Europe, but on about the same geological horizon, certainly belong, in M. Boule's opinion, to one type. Its mandible also presents the characters of the fossil mandibles, of the same age, known as Naulette, Spy, and Malarnaud. In the same palæontologist's estimation, the Neanderthal type should be considered a normal human tvpe, characteristic of certain parts of Europe in the Middle Pleistocene. This type is different from, and lower than, any now living, for in no existing race are to be found united the low characters seen in the La Chapelle-aux-Saints cranium.

M. Boule, however, is not prepared to separate the Neanderthal-Spy-La Chapelle-aux-Saints group generically, but he would not hesitate to distinguish the La Chapelle-au-Saints man specifically from those of all other human groups, living or fossil. He considers it certain that the Neanderthal-Spy-La Chapelleaux-Saints group represents a low type, nearer to the anthropoid apes than to any human group, and morphologically he would place them between Pithecanthropus and the lowest living races, yet without implying that they are in the same genetic line. The men of the Middle Pleistocene, judged by their physical characters and the relics of their industry, were in a primitive condition intellectually; while those who lived during the Upper Pleistocene possessed mental powers of a much higher order and were capable of producing true works of art, and their crania acquired the principal characters-the fine forehead, large brain, heaven-surveying countenance-of Homo sapiens.

A special interest attaches to the description given above of this new type of Homo, when we recall the various drawings of supposed "humans" left us by the men of the Upper Pleistocene on reindeer horn, ivory, and fragments of schist. These artists have depicted for us an extensive zoological picture-gallery, with a fidelity to nature hardly to be surpassed by any present-day artist. Their sketches are all from subjects with which they were intimately acquainted, and if there be forms among them which so far have not been recognised by us, we may rest assured that they were also reproduced from actual models. Among the palæolithic engravings much criticised are those of various anthropoid forms-such as the two accompanying examples (Figs. I and 2) from M. Piette and MM. Cartailhac and Breuil-which some ethnologists have hesitated to recognise as human, because of their pronounced simian characters.

The description given above of the man of La Chapelle-aux-Saints seems tor fit, in his snout-like jaws; semi-erect attitude, gibbonlike nose (especially Fig. 2), with wonderful exactitude, the drawings preserved to us at Mas d'Azil and elsewhere. Two very interesting questions suggest themselves: Are these pictures of a race surviving from the Middle Pleistocene? and, Were the artists of the Reindeer age depicting individuals of their own race? The present writer is convinced, and has long held, that they certainly depicted people contemporaneous with themselves, and reproduced them

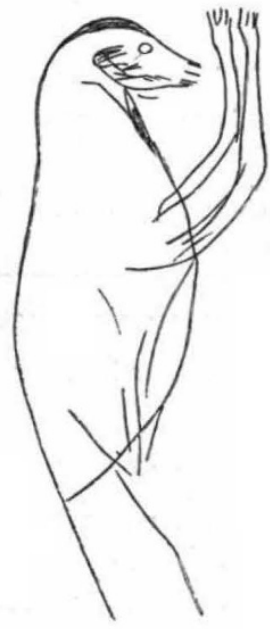

FIG. I.

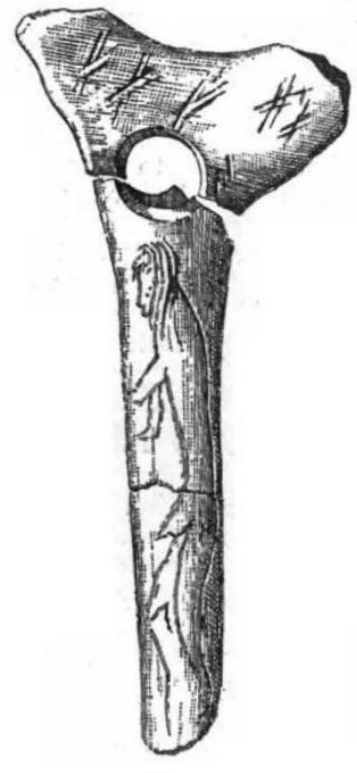

FrG. 2. as accurately as they did the bisons, horses, and rhinoceroses amid which they lived.

H. O. F.

\section{BLACK-WATER FEVER.'}

WE have before us a very careful and detailed study of one of the most dangerous of tropical diseases, which has numbered many victims amongst Europeans of all ranks and classes in various parts of the world; the public that reads Nature will not need to be reminded of the sad death of that distinguished zoologist, Mr. J. S. Budgett, from blackwater consequent on malaria contracted during his collecting expeditions in Africa.

The authors are especially concerned with the question of the nature and origin of black-water fever; the prophylaxis and treatment of the disease are dealt with very briefly. After a historical introduction the etiology of black-water fever is discussed and narrowed down to two alternative hypotheses, (I) that the disease is due to a specific organism, (2) that it is of malarial origin. It is then shown that the disease is not due to any parasite visible to critical microscopical examination, and that " the trend of evidence is steadily in favour of a malarial, as against a specific, origin." Facts are brought forward to show that in black-water fever the process of blooddestruction is what the authors propose to call "lysæmia," namely, "that condition, in which the red cells undergo solution in the plasma, and in which 1 "Black.water Fever." By S. R. Christophers and C. A. Bentley. Scientific Memoirs by Officers of the Medical and Sanitary Departments of the Government of India, No. 35. Pp. iv +239 . 
results true hæmoglobinæmia followed by hæmoglobinuria." Parasitic, osmotic, and chemical actions having been excluded as causes, it seems to the authors " most probable that black-water fever is due to some specific hremolysin arising within the body" as the result of certain conditions, induced by repeated attacks or infections by malaria. The hæmolysin is believed not to be derived from the malarial parasites themselves, but to be thrown out by the cells of the body in response to stimulation, as a result of the constant phagocytosis of red cells. "If hremolysins are formed against the blood there seems no agent so likely to effect this as the endothelium." The prophylaxis of black-water fever is " simply the prevention, as far as possible, of malarial infection, and the prompt and efficient treatment of this disease." In the palliative treatment of black-water fever the authors wish to show that "there are excellent reasons for believing that good results may be expected from serum-therapy."

The Goveriament of India is greatly to be congratulated on the enlightened manner in which it aids forward the production, and undertakes the publication, of important and valuable investigations of this kind.

\section{ANIMATED PHOTOGRAPHS IN NATURAL COLOURS.}

- $\mathrm{HE}$ production of photographs in colour by means that may fairly be described as photographic is now quite common. Though the simple method of getting pigmentary colours in the picture by the direct impact of the coloured lights proceeding from the object has not been, and may never be, realised, except, perhaps, to a certain extent by very prolonged exposures, the indirect three-colour process in its numerous modifications has thoroughly established itself as a quite practical method. It is natural, therefore, that endeavours to get kinematograph views shown on the sheet in natural colours should follow on the same lines that have made such great successes possible in single photographs.

Three-colour projection involves the taking of three negatives and the making from these of three suitably coloured positive transparencies which may then be superposed to form a single coloured transparency, or, using suitable colours, projected by three lanterns separately upon the screen and superposed there. The latter method would obviously commend itself in kinematography, because of the difficulty, if not the impossibility, of uniting three long strips into one, maintaining correct superposition from one end to the other. Besides, three lanterns would obviously give a good illumination on the screen more readily than one lantern. Many attempts, or at least suggestions, for it is difficult to know whether a verbal description really means anything more, have been made in this direction. Mr. G. Albert Smith, in a lecture recently given at the Royal Society of Arts, described the difficulties he met with in a really practical and persevering attempt, in conjunction with $\mathrm{Mr}$. Charles Urban, to succeed on these lines. There was not only the difficulty of photographing with the necessarily short exposure through the red screen, which was eventually overcome, but the practical impossibility of getting correct, or even passably correct, registration of the three pictures on the screen. This is a very different problem in kinematography from the production of a single three-colour picture. Obviously the three series of photographs must be taken simultaneously, and although the three kinematograph cameras may be synchronised, as they are necessarily somewhat bulky, the three points of view must be separated, and this introduces differences in the pic- tures analogous to the differences between the individuals of a stereoscopic pair. But this is not the only difficulty. It is comparatively easy to get three pictures on the screen from three lanterns or a triple lantern correctly superposed when the lanterns are quite still; but it is a very different matter in the case of kinematograph projection apparatus, for here the film runs through it in a series of rapid jerks, and the slightest movement of the apparatus produces a very much increased effect on the screen, because of the very considerable magnification necessary. Mr. tlbert Smith describes the result of his best attempts is " unbearable confusion."

All the mechanical difficulties of registration, and the dissimilarity of the photographs taken from three points of view, are done away with by using one film only and allowing the three coloured images to alternate. This has, further, the very great advantage of simplification, for the apparatus for taking and projecting is single only instead of three-fold. Ot course, the film must pass more quickly through the apparatus, as it requires three pictures to form the single complete impression instead of one. The difficulties of this are obvious in a general sense, and it also means a shortening of the exposure time in taking the pictures, a disadvantage especially with the red and green screens. Still, the method was successfu1, but Mr. Albert Smith found the colours to be "washy and ineffective." It is not obvious why this must needs be so; probably the defect might have been remedied, but Mr. Smith applied himself to further simplification, and aimed, in spite of theory, at reducing the colour records to two. In this he has been surprisingly successful, as his demonstrations show. It is not easy to follow his reasoning as to the most suitable colours, but as a matter of fact it seems that he uses a red inclining to orange and a green inclining to blue. The two colour screens are on a disc that rotates in front of the lens so that each alternate picture is taken and afterwards projected through the one colour. Thus the ordinary apparatus is available by the addition of the rotating disc that carries the colour screens, there is no difficulty with regard to registration, and the increase in speed of working, as compared with the ordinary kinematography, is doubled only instead of tripled. Doubtless there are imperfections in the colours, but the same may be said of all three-colour work. It has, however, been demonstrated that greys are fairly well reproduced, and that there are no striking errors even in such compound colours as purples. A comparison of the results so obtained with an autochrome slide made of the same view shows practically no difference to the ordinary observer. We may therefore say that Mr. Albert Smith's method is not only very good as a first step towards kinematography in colours, but that it is a really practical method.

\section{PROF. H. G. SEELEY, F.R.S.}

THE death of Prof. H. G. Seeley, which took place at his residence on the morning of January 8 , makes a big gap in the ranks of the comparatively small body of British vertebrate palæontologists, among whom the deceased professor was entitled to rank as the doyen. Born in London in February, I839, he seems to have acquired literary and scientific tastes at an early age, and in the 'sixties we find him established at Cambridge, where he was taken up by the late Prof. Adam Sedgwick, and employed to work at the fossil vertebrates then being rapidly accumulated in the Woodwardian Museum, and likewise to lecture on geology when the aged professor was incapacitated from doing so by infirmity or illness. It was at this time that the so-called coprolite diggings

No. 2046, VOL. 79] 